\title{
Commentary: Short Body Height and Pre-pregnancy Overweight for Increased Risk of Gestational Diabetes Mellitus: A Population-Based Cohort Study
}

\author{
Giridhara R. Babu ${ }^{1 *}$, Akinobu Nakamura ${ }^{2}$ and Dubravka Jurišić Eržen ${ }^{3}$ \\ ${ }^{1}$ Epidemiology, Public Health Foundation of India, New Delhi, India, ${ }^{2}$ Hokkaido University, Sapporo, Japan, ${ }^{3}$ Faculty of \\ medicine, University of Rijeka, Rijeka, Croatia
}

Keywords: diabetes, height, Asians, type 2 diabetes mellitus, screening, short stature

\section{OPEN ACCESS}

Edited by:

Wei Bao,

University of lowa, United States

Reviewed by:

Claudio Daniel Gonzalez,

Centro de Educación Médica e Investigaciones Clínicas Norberto

Quirno (CEMIC), Argentina

*Correspondence:

Giridhara R. Babu

epigiridhar@gmail.com

Specialty section:

This article was submitted to

Diabetes,

a section of the journal

Frontiers in Endocrinology

Received: 08 July 2018 Accepted: 10 September 2018

Published: 12 October 2018

Citation

Babu GR, Nakamura $A$ and Jurišić Eržen D (2018) Commentary:

Short Body Height and Pre-pregnancy

Overweight for Increased Risk of

Gestational Diabetes Mellitus: A

Population-Based Cohort Study.

Front. Endocrinol. 9:575.

doi: 10.3389/fendo.2018.00575

\section{A Commentary on}

Short Body Height and Pre-pregnancy Overweight for Increased Risk of Gestational Diabetes Mellitus: A Population-Based Cohort Study.

by Li J, Wang P, Zhang C, Leng J, Li N, Wang L., et al. (2018). Front. Endocrinol. 9:349. doi: $10.3389 /$ fendo.2018.00349

$\mathrm{Li} \mathrm{J}$ et al. conduct a sufficiently large cohort study and show that the risk of gestational diabetes mellitus (GDM) is inversely correlated with the height of the pregnant women (1). This association is particularly seen among Asians and may not warrant biological plausibility for using short stature as screening criteria due to several reasons (2).

First, short stature can be associated principally through the mechanism of greater risk of obesity/fat mass (3). Co-presence of short stature and overweight in the pre-pregnant women might be more useful screening criteria (4). Second, the same adaptive alterations that protected these women from undernourishment during their early development could have led them to short stature, as well as lead to glucose intolerance (thrifty phenotype hypothesis) $(5,6)$. It is also possible that a genetically determined insulin effect could lead to both failure to grow and to diabetes (thrifty genotype); which might have contributed to a predisposition for $\operatorname{GDM}(7,8)$.

GDM, as a form of diabetes is multifactorial disease in origin. Several factors such as greater prepregnancy BMI, age, weight gain and a parental history of diabetes mellitus are independently associated with the GDM (9). The epidemiologic studies using the selective criteria such as height as a risk factor may not mean much in a heterogeneous population with different types of genetic lineage and environmental influences. Height is merely a function of nutrition and genetic lineage; therefore, measuring the height of the women in childbearing age will not reflect undernourishment or frequent infections in their infancy and through their life-course. Future studies have to reflect height as an intermediate variable between early exposures in fetal and childhood with subsequent risk of non-communicable diseases including the GDM. 


\section{AUTHOR CONTRIBUTIONS}

GB wrote the first draft and reviewed all drafts of the commentary. AN reviewed and provided inputs for finalization of the commentary. DJ reviewed and provided inputs for finalization of the commentary through all stages.

\section{REFERENCES}

1. Li J, Wang P, Zhang C, Leng J, Li N, Wang L, et al. Short body height and pre-pregnancy overweight for increased risk of gestational diabetes mellitus: a population-based cohort study. Front Endocrinol. (2018) 9:349. doi: 10.3389/fendo.2018.00349

2. Brite J, Shiroma E, Bowers K, Yeung E, Laughon S, Grewal J, et al. Height and the risk of gestational diabetes: variations by race/ethnicity. Diabetic Med. (2014) 31:332-40. doi: 10.1111/dme.12355

3. Desai M, Jellyman J, Ross M. Epigenomics, gestational programming and risk of metabolic syndrome. Int J Obesity (2015) 39:633. doi: 10.1038/ijo. 2015.13

4. Branchtein L, Schmidt MI, Matos M, Yamashita T, Pousada JMDC, Duncan $\mathrm{BB}$, et al. Short stature and gestational diabetes in Brazil. Diabetologia (2000) 43:848-51. doi: 10.1007/s001250051460

5. Asao K, Kao WHL, Baptiste-Roberts K, Bandeen-Roche K, Erlinger TP, Brancati FL. Short stature and the risk of adiposity, insulin resistance, and type 2 diabetes in middle age. The Third National Health and Nutrition Examination Survey (NHANES III), 1988-1994. Diabetes Care (2006) 29:16327. doi: $10.2337 / \mathrm{dc} 05-1997$

6. Hales CN, Barker DJ. The thrifty phenotype hypothesis. Br Med Bull. (2001) 60:5-20. doi: $10.1093 / \mathrm{bmb} / 60.1 .5$

\section{ACKNOWLEDGMENTS}

This work is supported by the Wellcome Trust DBT India Alliance Fellowship to GB (Grant Number: IA/CPHI/14/1/501499).

7. Dunger DB, Ong KK, Huxtable SJ, Sherriff A, Woods KA, Ahmed ML, et al. Association of the INS VNTR with size at birth. Nat Genet. (1998) 19:98. doi: 10.1038/ng0598-98

8. Terauchi Y, Kubota N, Tamemoto H, Sakura H, Nagai R, Akanuma Y, et al. Insulin effect during embryogenesis determines fetal growth: a possible molecular link between birth weight and susceptibility to type 2 diabetes. Diabetes (2000) 49:82-6. doi: 10.2337/diabetes.49.1.82

9. Jang H, Min H, Lee H, Cho N, Metzger B. Short stature in Korean women: a contribution to the multifactorial predisposition to gestational diabetes mellitus. Diabetologia (1998) 41:778-83. doi: 10.1007/s001250050987

Conflict of Interest Statement: The authors declare that the research was conducted in the absence of any commercial or financial relationships that could be construed as a potential conflict of interest.

Copyright (C) 2018 Babu, Nakamura and Jurišić Eržen. This is an open-access article distributed under the terms of the Creative Commons Attribution License (CC BY). The use, distribution or reproduction in other forums is permitted, provided the original author(s) and the copyright owner(s) are credited and that the original publication in this journal is cited, in accordance with accepted academic practice. No use, distribution or reproduction is permitted which does not comply with these terms. 